\title{
MR Thermography-Guided Head and Neck Lesion Laser Ablation
}

\author{
(DD.T. Ginat, ${ }^{D}$ S. Sammet, and ${ }^{D}$ G. Christoforidis
}

\begin{abstract}
SUMMARY: Interstitial laser ablation has been successfully used as a minimally invasive treatment option for tumors in many parts of the body, including the head and neck. In this article, we describe the use of MR imaging guidance and mapping sequences for accurate localization of the target lesion, percutaneous interstitial laser ablation methods, and the use of MR thermography for temperature monitoring during laser ablation, with a focus on applications in the head and neck region.
\end{abstract}

L aser ablation, also known as interstitial laser ablation/thermal therapy or stereotactically guided interstitial laser thermal ablation, is a minimally invasive treatment technique that can be performed as an outpatient percutaneous procedure. The technique uses the phenomenon that heat-induced protein denaturation and coagulative necrosis occur at temperatures above $43^{\circ} \mathrm{C}$, such that the time to cell death varies exponentially with temperature. ${ }^{1}$ This is accomplished with light at wavelengths of 800-1064 nm from diode or neodymium-doped yttrium aluminum garnet lasers, which is absorbed by chromophores in tissues, leading to the release of thermal energy. ${ }^{2}$

Commercial fiber-optic laser tips can be cooled using fluids, which allow higher initial power use without damaging the fiberoptic tip. The cooling process also removes heat from the probetissue interface, thereby preventing carbonization or vaporization and enabling the creation of larger ablation volumes. Furthermore, cooling prevents the probe tip from adhering to the ablated tissue. ${ }^{1}$ Laser ablation of soft tissues results in 5 distinct concentric zones: 1) a core that corresponds to the probe tract; 2) a central zone of coagulation necrosis that contains damaged cell membranes and stains positive for markers of apoptosis; 3) a peripheral zone that contains thrombosed vessels and distended cell bodies, followed by liquefaction necrosis; 4) a peripheral rim of leaky vasculature; and 5) a marginal zone of reversible edema. ${ }^{3,4}$ The

Received January 1, 2018; accepted after revision April 19

From the Department of Radiology, University of Chicago, Pritzker School of Medicine, Chicago, Illinois.

This work was supported by Toshiba America Medical Systems/RSNA Research Seed Grant.

Please address correspondence to Daniel Thomas Ginat, MD, MS, Department of Radiology, University of Chicago, Pritzker School of Medicine, 5841 S Maryland Ave, Chicago, IL 60637; e-mail: dtg1@uchicago.edu

http://dx.doi.org/10.3174/ajnr.A5726 volume of the necrosis induced by laser ablation depends on the probe size, duration of the procedure, and temperature setting. Larger lesions may require multiple probes or serial laser ablation with repositioning of the probe. Ultimately, laser ablation produces a sharp transition zone between dead and viable tissue.

Interstitial laser ablation has several advantages over other thermal therapy methods. Unlike high-intensity focused sonography, laser ablation is rapid and is less affected by target motion and heats more slowly. Unlike radiofrequency ablation, the laser fiber does not produce large MR imaging artifacts caused by electromagnetic interferences. ${ }^{5,6}$ Thus, laser ablation can be used simultaneously with real-time MR temperature monitoring. Furthermore, patients who undergo percutaneous interstitial laser ablation tend to be discharged after a shorter stay compared with open surgical procedures. ${ }^{2,7-12}$ Consequently, interstitial laser ablation has been found to be a cost-effective option for treating brain tumors. For example, this technique is less costly than craniotomy for patients with brain metastases. ${ }^{13}$ Furthermore, interstitial laser ablation improves survival of patients with highgrade gliomas at a cost that appears to be of good value to society. ${ }^{14}$ Although there is a paucity of data regarding the cost-effectiveness of interstitial laser ablation for head and neck lesions, we believe that in many cases, the procedure can provide good value as well.

\section{Head and Neck Laser Ablation Indications and Complications}

Laser ablation has been successfully performed for treating various lesions in the head and neck, brain, breast, liver, prostate, and colon among other sites. ${ }^{2,7-12,15-22}$ Regarding the head and neck in particular, percutaneous laser ablation has been implemented for treating benign solid thyroid nodules, lymphatic malforma- 
tions, and various malignant neoplasms. ${ }^{8,9,16-22}$ Laser ablation performed to shrink symptomatic benign solid thyroid nodules has been reported to yield a $47 \%-82 \%$ reduction in volume, a minor complication rate of $38 \%$, and a major complication rate of $3 \% .^{22}$ Major complications related to laser ablation of benign solid thyroid nodules include dysphonia, nodule rupture, hypothyroidism, and brachial plexus injury, while minor complications include hematoma, vomiting, skin burn, pain, edema, fever, and coughing, ${ }^{22}$ though many of the procedures were not performed under MR thermography guidance.

In a small study of lymphangiomas in the tongue and neck, MR imaging-guided laser ablation performed via a percutaneous approach using a multiapplicator technique resulted in a considerable decrease in the size of all lesions by 3 months, with improvement in functions such as speech and swallowing in most patients. ${ }^{20}$ In particular, the cystic components showed the most change as the treated lymphatic channels become surrounded by fibrous tissue. Recurrence of the lymphatic malformations is nevertheless a possibility, but laser ablation of these lesions can be performed to facilitate subsequent debulking surgery.

Recurrent head and neck cancers after major surgery and/or radiation therapy are difficult to manage via conventional treatment methods. Laser ablation is a relatively safe treatment option for recurrent head and neck cancers for which surgery is limited by the proximity of vital neurovascular structures and the aggressive nature of these tumors. ${ }^{19}$ A $78 \%$ partial or complete response and a median survival of 19 months was achieved for recurrent head and neck cancers treated with laser ablation, which surpasses the results obtained via a standard regimen of cisplatin/fluorouracil (5-FU). ${ }^{8}$ In particular, oral cavity squamous cell carcinomas showed the greatest response to the procedure. ${ }^{8}$ Furthermore, laser ablation reduces clinical symptoms in most patients. Infusion of chemotherapy into the ablated tumor can potentially augment the effects of laser thermal therapy while mitigating systemic toxicity and is the subject of investigation. ${ }^{8}$

\section{MR Imaging Guidance for Head and Neck Laser Ablation}

Various navigation techniques and devices have been developed for MR imaging-guided interventions. ${ }^{23-25}$ The advantages and disadvantages mainly depend on the type of the MR imaging scanner and the interventional environment. ${ }^{23}$ For example, open MR imaging scanners require minimal patient transfer during the procedure, which facilitates the interventional workflow. On the other hand, while most high-field-strength closed-bore MR imaging scanners provide better image quality, they do not enable instruments to be inserted within the bore of the magnet. Consequently, interventions in closed-bore scanners require the patient being moved out of the bore, though multimodal overlays, augmented reality displays, and robotic assistance devices can facilitate the process. $^{23}$

Insertion of the laser probe can be accomplished under MR imaging using freehand or stereotactic approaches. In either case, the device can be advanced into the target lesion under MR imaging "fluoroscopic" guidance, in which the choice of tissue contrast weighting can be tailored to maximize lesion conspicuity on the basis of preprocedural imaging. Furthermore, MR imaging pro-

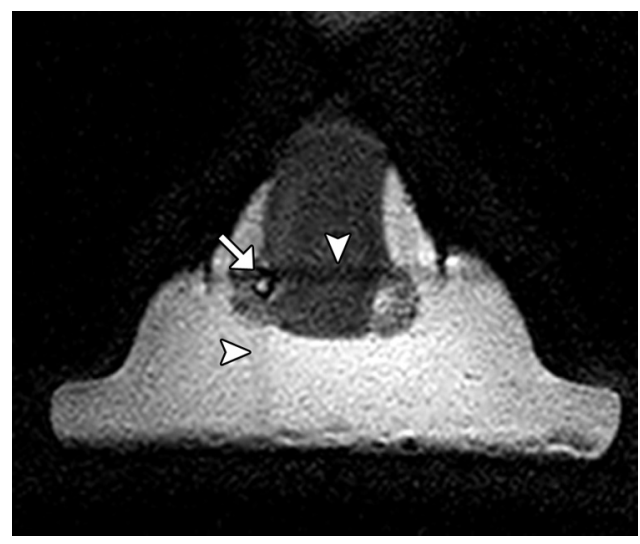

FIG 1. MR imaging guidance for laser applicator insertion. 3D T1weighted fast-field echo image shows saturation bands (arrowheads) that are used to triangulate the target "lesion" (arrow) in the neck phantom.

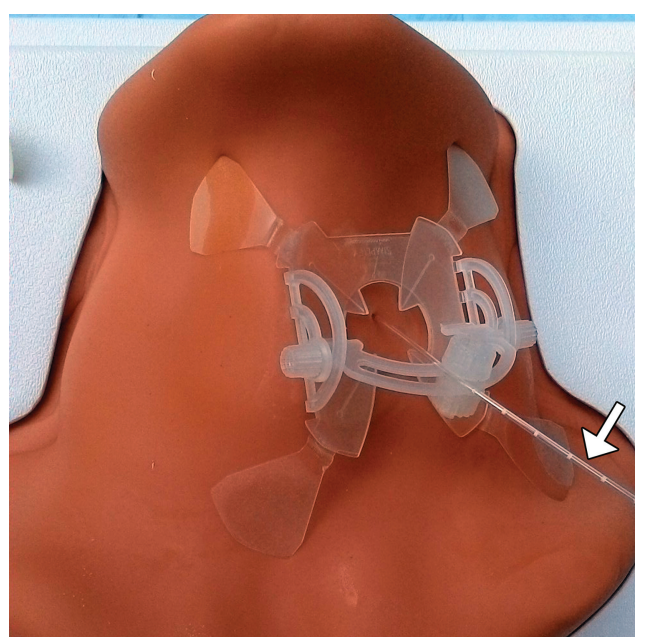

FIG 2. Photograph shows the laser applicator (Medtronic, Minneapolis, Minnesota) (arrow) inserted into the neck phantom (CIRS, Norfolk, Virginia) and supported by a skin-adhesive device (NeoRad).

vides the ability to continuously visualize vessels throughout a procedure without using intravenous contrast.

Lesion targeting has traditionally been performed using "inand-out" techniques in closed-bore MR imaging scanners with control imaging performed inside the bore, and needle adjustments, outside the bore. Alternatively, the process of targeting the lesion can be expedited using guidance and navigation systems, such as virtual 3D-MR imaging with real-time overlay of an optically tracked biopsy needle using reference markers or the interventional MR imaging suite (iSuite) image guidance and mapping system (Philips Research Labs, Hamburg, Germany), which facilitates triangulation of the laser probe insertion trajectory (Fig 1). ${ }^{26}$ The biopsy needles and laser probe used for the procedure can be secured in position using commercially available skin-adhesive holder devices, such as the Simplify needle holder (NeoRad, Oslo, Norway) or Cradles Needle Localization Wire Protectors (Beekley Medical, Norcross, Georgia) (Fig 2).

\section{MR Thermography}

In general, the success of laser interstitial thermal ablation depends on accurate insertion of the laser fiber into the target lesion, 


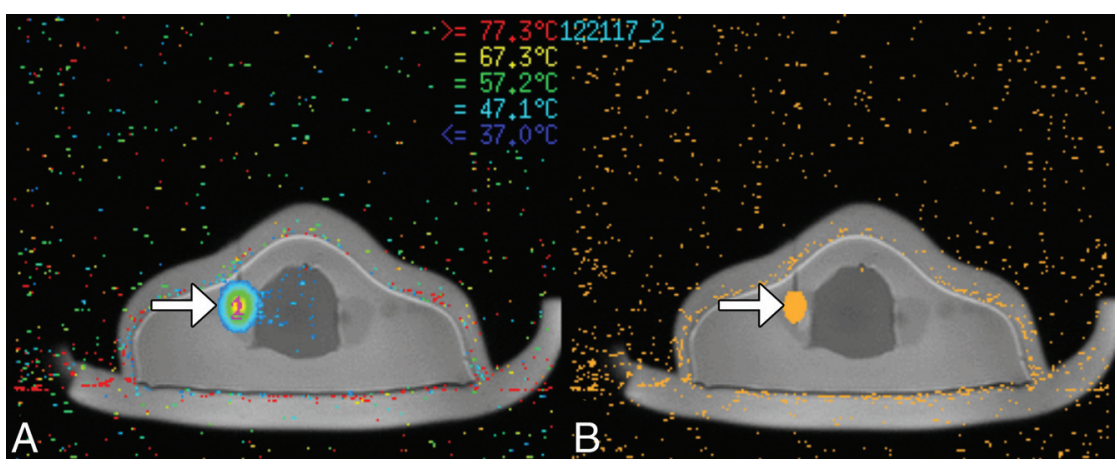

FIG 3. MR thermography during laser ablation. Temperature map acquired using the proton resonance frequency shift $(A)$ and heat-damage model in a neck phantom $(B)$ shows the ablation zone surrounding the tip of the probe (arrows). neck lesions, including benign thyroid nodules, vascular malformations, and cancers with low complication rates. In particular, the use of MR imaging guidance for inserting the laser applicator and the use of MR thermography for monitoring temperature changes during the procedure can help optimize safety and efficacy.

\section{ACKNOWLEDGMENTS}

We thank Amy Schneider of Medtronic for assistance in performing the laser ablation procedure. real-time monitoring of the effects of the treatment, and subsequent evaluation of the extent of thermal tissue damage. ${ }^{19} \mathrm{MR}$ thermography is a validated noninvasive imaging technique that can provide accurate monitoring during laser ablation. ${ }^{19,27} \mathrm{Sev}-$ eral MR thermography methods have been developed, including sequences based on the proton resonance frequency, the diffusion coefficient, T1 and T2 relaxation times, magnetization transfer, proton density, and temperature-sensitive contrast agents. ${ }^{4,24,27}$ In particular, proton resonance frequency techniques use temperature-induced effects of chemical shift, in which the temperature difference is directly proportional to the phase difference. This method provides accurate temperature measurements in the temperature range of interest for thermal ablation. ${ }^{24}$

A thermal dose can be calculated from a map of temperature as a function of time and is used for the prediction of tissue destruction (Fig 3). ${ }^{7}$ Ultimately, continuous MR thermometry during thermal ablation procedures can help optimize safe thermal therapy delivery. Although the adequacy of ablation is estimated on the basis of the laser ablation system-generated damage model, it is important to obtain an immediate postablation MR imaging scan to ensure adequate ablation of the lesion.

Important technical considerations for performing MR imaging-guided laser ablation include coil selection and assessing the quality of MR imaging sequences in the head and neck region. For example, the use of whole-body coils contained within the closed bore of a high-field-strength MR imaging scanner is an ergonomic option with fewer obstacles between the interventionalist and the patient. Although these types of coils yield lower signal-to-noise compared with head and neck neurovascular coils, for example, the image quality may be generally adequate for clinical use. ${ }^{28}$

Furthermore, the quality of MR thermography can be limited by the presence of susceptibility artifacts from hemorrhage, calcifications, or underlying surgical hardware; the excessive presence of fat surrounding the lesion; and misregistration artifacts related to motion. ${ }^{3}$ Ultimately, interstitial laser ablation should be performed only with MR thermography if a lesion can be adequately discerned on MR thermography images obtained as part of the pretreatment MR imaging.

\section{CONCLUSIONS}

Interstitial laser ablation is a minimally invasive and potentially cost-effect technique that can be used to treat a variety of head and

\section{REFERENCES}

1. Mensel B, Weigel C, Hosten N. Laser-induced thermotherapy. Recent Results Cancer Res 2006;167:69-75 CrossRef Medline

2. Stafford RJ, Fuentes D, Elliott AA, et al. Laser-induced thermal therapy for tumor ablation. Crit Rev Biomed Eng 2010;38:79-100 CrossRef Medline

3. Medvid R, Ruiz A, Komotar RJ, et al. Current applications of MRIguided laser interstitial thermal therapy in the treatment of brain neoplasms and epilepsy: a radiologic and neurosurgical overview. AJNR Am J Neuroradiol 2015;36:1998-2006 CrossRef Medline

4. Schober R, Bettag M, Sabel M, et al. Fine structure of zonal changes in experimental Nd:YAG laser-induced interstitial hyperthermia. Lasers Surg Med 1993;13:234-41 CrossRef Medline

5. Kickhefel A, Rosenberg C, Weiss CR, et al. Clinical evaluation of MR temperature monitoring of laser-induced thermotherapy in human liver using the proton-resonance-frequency method and predictive models of cell death. J Magn Reson Imaging 2011;33:704-12 CrossRef Medline

6. Boss A, Graf H, Müller-Bierl B, et al. Magnetic susceptibility effects on the accuracy of MR temperature monitoring by the proton resonance frequency method. J Magn Reson Imaging 2005;22:813-20 CrossRef Medline

7. Oto A, Sethi I, Karczmar G, et al. MR imaging-guided focal laser ablation for prostate cancer: phase I trial. Radiology 2013;267: 932-40 CrossRef Medline

8. Sercarz JA, Bublik M, Joo J, et al. Outcomes of laser thermal therapy for recurrent head and neck cancer. Otolaryngol Head Neck Surg 2010;142:344-50 CrossRef Medline

9. Joo J, Sercarz JA, Paolini AA, et al. Laser-induced thermal therapy and cisplatin for recurrent head and neck cancer: a case characterized by an unusually long disease-free survival. Ear Nose Throat J 2009;88:E13-E16 Medline

10. Banerjee C, Snelling B, Berger $\mathrm{MH}$, et al. The role of magnetic resonance-guided laser ablation in neurooncology. Br J Neurosurg 2015; 29:192-96 CrossRef Medline

11. Carpentier A, McNichols RJ, Stafford RJ, et al. Laser thermal therapy: real-time MRI-guided and computer-controlled procedures for metastatic brain tumors. Lasers Surg Med 2011;43:943-50 CrossRef Medline

12. Carpentier A, McNichols RJ, Stafford RJ, et al. Real-time magnetic resonance-guided laser thermal therapy for focal metastatic brain tumors. Neurosurgery 2008;63:ONS21-28; discussion ONS28-29 Medline

13. Leuthardt EC, Voigt J, Kim AH, et al. A single-center cost analysis of treating primary and metastatic brain cancers with either brain Laser Interstitial Thermal Therapy (LITT) or craniotomy. Pharmacoecon Open 2017;1:53-63 CrossRef Medline

14. Voigt JD, Barnett G. The value of using a brain laser interstitial thermal therapy (LITT) system in patients presenting with high 
grade gliomas where maximal safe resection may not be feasible. Cost Eff Resour Alloc 2016;14:6 CrossRef Medline

15. Eckardt A, Barth EL, Kokemueller H, et al. Recurrent carcinoma of the head and neck: treatment strategies and survival analysis in a 20-year period. Oral Oncol 2004;40:427-32 CrossRef Medline

16. Pacella CM, Bizzarri G, Spiezia S, et al. Thyroid tissue: US-guided percutaneous laser thermal ablation. Radiology 2004;232:272-80 CrossRef Medline

17. Shahrzad MK. Laser thermal ablation of thyroid benign nodules. $J$ Lasers Med Sci 2015;6:151-56 CrossRef Medline

18. Achille G, Zizzi S, Di Stasio E, et al. Ultrasound-guided percutaneous laser ablation in treating symptomatic solid benign thyroid nodules: our experience in 45 patients. Head Neck 2016;38: 677-82 CrossRef Medline

19. Mack MG, Vogl TJ. MR-guided ablation of head and neck tumors. Neuroimaging Clin N Am 2004;14:853-59 CrossRef Medline

20. Eyrich GK, Bruder E, Hilfiker P, et al. Temperature mapping of magnetic resonance-guided laser interstitial thermal therapy (LITT) in lymphangiomas of the head and neck. Lasers Surg Med 2000;26: 467-76 CrossRef Medline

21. Feyh J, Gutmann R, Leunig A, et al. MRI-guided laser interstitial thermal therapy (LITT) of head and neck tumors: progress with a new method. J Clin Laser Med Surg 1996;14:361-66 Medline

22. Mainini AP, Monaco C, Pescatori LC, et al. Image-guided thermal ablation of benign thyroid nodules. J Ultrasound 2017;20:11-22 CrossRef Medline

23. Moche M, Trampel R, Kahn T, et al. Navigation concepts for MR image-guided interventions. J Magn Reson Imaging 2008;27:276-91 CrossRef Medline

24. Weiss CR, Nour SG, Lewin JS. MR-guided biopsy: a review of current techniques and applications. J Magn Reson Imaging 2008;27: 311-25 CrossRef Medline

25. Cleary K, Peters TM. Image-guided interventions: technology review and clinical applications. Annu Rev Biomed Eng 2010;12: 119-42 CrossRef Medline

26. Busse H, Riedel T, Garnov N, et al. Targeting accuracy, procedure times and user experience of 240 experimental MRI biopsies guided by a clinical add-on navigation system. PLoS One 2015;10:e134370 CrossRef Medline

27. Quesson B, de Zwart JA, Moonen CT. Magnetic resonance temperature imaging for guidance of thermotherapy. J Magn Reson Imaging 2000;12:525-33 CrossRef Medline

28. Ginat DT, Anthony GJ, Christoforidis G, et al. Comparison between whole-body and head and neck neurovascular coils for 3-T magnetic resonance proton resonance frequency shift thermography guidance in the head and neck region. Lasers Med Sci 2018;33: 369-73 CrossRef Medline 